\title{
Methadone Deaths in Pain and Addiction Populations
}

To the Editors: - The article in your April 2010 edition by Modesto-Lowe et al. ${ }^{1}$ titled "Methadone Deaths: Risk Factors in Pain and Addicted Populations" provided an excellent discussion of methadone in opioid addiction treatment. However, we found that their discussion regarding methadone use as an analgesic understated the risks and overstated our ability to reduce these risks.

As the authors discussed, the high rate of methadone mortality is due to two very unfavorable properties which are unique to methadone among the marketed opioids. First, methadone use has a risk of death from Torsade de pointes. Modesto-Lowe et al. ${ }^{1}$ devote a great deal of discussion to reducing methadone mortality by reducing the risk of Torsade de pointes. However, of 5,503 adverse events from methadone reported from 1969 to October 2002, only 0.78\% were for Torsades de pointes and $0.29 \%$ were for $\mathrm{QT}$ prolongation ${ }^{2}$. Thus, while attempting to reduce the incidence of Torsade de pointes is certainly worthwhile, it is not likely to have a major impact on reducing methadone mortality.

As noted by Modesto-Lowe et al. ${ }^{1}$, the second of methadone's very unfavorable properties is that its respiratory depressant effect persists much longer than its analgesic effect. This inherent property of methadone cannot be altered by risk reduction strategies. Repeated dosing to control pain often leads to drug accumulation causing respiratory depression resulting in hypoxic brain injury or death.

Citing Trescot et al. ${ }^{3}$ and Shaiova et al. ${ }^{4}$, Modesto-Lowe et al. ${ }^{1}$ stated that methadone treatment for chronic pain has increased because of its long half-life, efficacy and low cost. However, the long-half life of methadone is for its respiratory depressant effect, not for its desired analgesic activity. Trescot et $\mathrm{al}^{3}$ found that the evidence for the efficacy of methadone in reducing pain and improving functional status for 6 months or longer is the weakest Level III (indeterminate). Shaiova et al. ${ }^{4}$ advocated the use of intravenous methadone in palliative care of patients with life-limiting illnesses, a much different patient

Published online June 8, 2010 population and method of administration than the vast majority of chronic pain patients being treated with methadone. Thus, the only real advantage of methadone for most chronic pain patients with non-terminal illnesses is its somewhat lower cost. Mandating methadone as a first-line analgesic by third-party payers is a root cause of methadone mortality ${ }^{5}$. A small financial savings does not justify the routine prescribing of this very dangerous analgesic.

Kenneth J. Grant, MD, Department of Family \& Community Medicine, University of New Mexico School of Medicine, 5555 Zuni SE, Suite 275, Albuquerque, NM 87108, USA; (e-mail: kjgrant@unm. edu); Catherine T. Baca, MD, Department of Pediatrics Adolescent Medicine (retired), University of New Mexico School of Medicine, Albuquerque, NM, USA.

\section{REFERENCES}

1. Modesto-Lowe V, Brooks D, Petry N. Methadone deaths: risk factors in pain and addicted populations. J Gen Intern Med. 2010;25(4):305-9.

2. Pearson EC, Woosley RL. QT prolongation and Torsades de pointes among methadone users: reports to the FDA spontaneous reporting system. Pharmacoepidemiol Drug Saf. 2005;14:747-53.

3. Trescot AM, Helm S, Hansen $\mathbf{H}$, et al. Opioids in the management of chronic non-cancer pain: an update of American Society of the Interventional Pain Physicians Guidelines. Pain Physician. 2008;11(2 suppl): S5-62.

4. Shaiova L, Berger A, Blinderman CD, et al. Consensus guideline on parenteral methadone use in pain and palliative care. Palliat Support Care. 2008;6:165-76.

5. Bateman K, Cochella S, Dove B, et al. Root cause analysis for unintentional overdose deaths involving opioids in chronic pain patients reveals disproportionate methadone involvement. Presented at: 2010 AAPM Annual Meeting; February 3-6, 2010; San Antonio, TX. Accessed at http://www.zerodeaths.org/event/?event_id=139 on April 25, 2010.

J Gen Intern Med 25(9):898 DOI: $10.1007 / \mathrm{s} 11606-010-1411-0$

(C) Society of General Internal Medicine 2010 